\title{
ORIENTAÇÃO SOBRE MÉTODOS CONTRACEPTIVOS NO PUERPÉRIO IMEDIATO.
}

Congresso Online Brasileiro de Medicina, 1a edição, de 06/12/2021 a 08/12/2021 ISBN dos Anais: 978-65-86861-87-7.

BRITO; Patricia Leite ${ }^{1}$

\section{RESUMO}

INTRODUÇÃO: O uso de métodos contraceptivos deve ser norteado por uma escolha pessoal da paciente, associado a critérios clínicos, éticos, sociais e culturais, sendo um importante recurso para diminuição do número de gravidez não planejadas, e do aumento do intervalo gestacional, em grupos populacionais vulneráveis como as adolescentes e dessa forma, contribuir para diminuição das taxas de abortamento e de mortalidade materna. Conhecer e ter acesso a informação sobre as opções e uso dos métodos existentes, é um direito da mulher, no seu exercício de cidadania e deveria ser um recurso utilizado em todos os momentos da trajetória dentro do serviço da rede básica de saúde, inclusive no pré-natal e no pós-parto. OBJETIVO: O trabalho pretende demonstrar uma ação exitosa realizada em maternidade pública terciária do Norte do país, onde se realizou um projeto de avaliação de conhecimento e orientação dos métodos contraceptivos, para pacientes no momento da internação para o parto, inclusive com a oferta e uso do Dispositivo Intra-uterino (DIU) de cobre, no pós-parto imediato, normal ou cesárea e no pós-aborto. METODOLOGIA: Estudo observacional e descritivo, de abordagem quantitativa, para avaliar a percepção e conhecimento sobre os métodos contraceptivos. As pacientes passavam por uma entrevista com a equipe de enfermagem, questionando sobre o conhecimento sobre os métodos contraceptivos e o desejo de realizar o uso e inserção do DIU após- o parto. As pacientes que não consentiam ou não desejavam realizar o método no momento do parto, eram novamente abordadas na enfermaria para nova palestra sobre a importância da prevenção de nova gravidez e da realização de consulta de acompanhamento do puerpério. Observamos, que a grande maioria não tinha conhecimento sobre os métodos existentes oferecidos, gratuitamente, no sistema de saúde e que o interessse sobre eles foi maior no momento da abordagem na enfermaria. RESULTADOS: A prática desempenhada demonstrou que é importante e necessário o estímulo e oferta da informação sobre os recursos existentes, para prevenção de nova gravidez, desmistificando e disponibilizando ao longo de todo processo de acesso ao atendimento da saúde da mulher, desde as consultas de rotina até no momento do pós-parto. CONCLUSÃO: Para diminuir as taxas de gravidez na adolescência, prematuridade, mortalidade materna e neonatal, devemos desenvolver medidas educacionais entre o público feminino em idade fértil, e melhorar o acesso aos métodos contraceptivos, melhorar a qualidade da assistência ofertada no cuidado da saúde da mulher e acima de tudo mobilizar recursos, para 
ampliar a educação sexual entre os jovens.

PALAVRAS-CHAVE: PÓS-PARTO, MÉTODOS CONTRACEPTIVOS, PUERPÉRIO 